\title{
Analysis on Base Forms of High-Frequency Predicates to Develop Augmentative and Alternative Communication Systems
}

\author{
Sangeun Shin \\ Department of Communication Disorders, Ewha Womans University, Seoul, Korea
}

Correspondence: Sangeun Shin, PhD Department of Communication Disorders, Ewha Womans University, 52 Ewhayeodae-gil, Seodamun-gu, Seoul 03760, Korea

Tel: $+82-2-3277-2120$

Fax: +82-2-3277-2122

E-mail: newvil78@gmail.com

Received: January 5, 2017

Revised: February 19, 2017

Accepted: February 21, 2017

This study is based on archived records of the Korean AAC core vocabulary study from Shin \& Hill (2016).

\begin{abstract}
Objectives: Core vocabulary is key to successful communication for people who rely on augmentative and alternative communication (AAC) systems. It is important to meet the needs of adult AAC users who want to produce a wide range of inflected predicates on the system. The purpose of the current study was to determine the high-frequency (HF) base forms of predicates and to predict the efficiency in generating various sentence types by using those base-forms that are combinable with numerous endings. Methods: Language samples from the twelve healthy adults were used and $216 \mathrm{HF}$ predicates in inflected forms were identified. After transforming all inflected forms into base forms, the number of different words, the mean frequency of a single HF predicate, and the percentage of total sample words that were accounted for by HF base-forms were calculated. The findings were compared with inflected forms of HF predicates. Results: Sixty-three base forms were identified. The mean frequency of single predicates was 53.83 , and $73.97 \%$ of the total sample's predicates were accounted for by HF base forms, which shows a great decrease in the number of different words, but a great increase in the mean frequency and the percentage of accountability. Conclusion: The current study provides evidence that a small number of HF base forms of predicates can be used efficiently to produce various types of inflected predicates by combining with endings. The need for developing effective AAC tools that reflect $\mathrm{HF}$ base verb forms is discussed.
\end{abstract}

Keywords: Core vocabulary, Augmentative and alternative communication, Predicate, Base form, High frequency, Adult
성공적인 보완대체의사소통(augmentative and alternative communication, $\mathrm{AAC}$ ) 중재를 위해서는 적절한 어휘를 선택하는 것이 중요하다(Beukelman, McGinnis, \& Morrow, 1991; Fallon, Light, \& Paige, 2001; Fried-Oken \& More, 1992; Johnson, Inglebret, Jones, $\&$ Ray, 2006). 아무리 다양한 기능이 탑재된 AAC 도구를 제공한 다 하더라도 사용자가 일상에서 자주 사용하는 낱말들이 누락된 다면 $\mathrm{AAC}$ 중재효과를 기대하기 어려울 것이다. 문헌에서는 효과 적인 $\mathrm{AAC}$ 체계 구축을 위한 첫 단계로 핵심어휘(core vocabulary) 를 판별하는 것에 관심을 기울여 왔다(Banajee, Dicarlo, \& Buras Stricklin, 2003; Beukelman, Jones, \& Rowan, 1989; Liu \& Sloane,
2006; Marvin, Beukelman, \& Bilyeu, 1994; Stuart, Beukelman, \& King, 1997; Trembath, Balandin, \& Togher, 2007). 핵심어휘란 발화 시 자주 출현하고 여러 사람에게서 공통적으로 사용되는, 즉 고빈 도이면서 공통성(word commonality)이 높은 어휘를 말한다(Banajee et al., 2003; Beukelman et al., 1989; Kim, Park, \& Min, 2003; Robillard, Mayer-Crittenden, Minor-Corriveau, \& Bélanger, 2014; Yorkston, Dowden, Honsinger, Marriner, \& Smith, 1988). 영어권 $\mathrm{AAC}$ 어휘 연구에 따르면 연령과 상관없이 약 250 개에서 350 개 사 이의 비교적 적은 수의 낱말들이 전체 발화의 약 78\%-85\%를 차지 하는 것으로 보고되고 있다(Balandin \& Iacono, 1999; Banajee et 
al., 2003; Beukelman et al., 1989; Hill, 2001; Stuart et al., 1997). 핵 심어휘에는 대명사, 전치사, 의문사, 접속사 등과 같은 문법적인 기 능을 나타내는 구조어와 동사, 형용사, 부사, 명사와 같은 내용어가 포함되어 있으며(Boenisch \& Soto, 2015; Trembath et al., 2007), 특 별히 의사소통 환경에 영향을 받지 않고 아동과 성인 간에도 높은 공통성을 보이는 것으로 보고되고 있다(Baker, Hill, \& Devylder, 2000; Banajee et al., 2003; Hill, 2001). 반면에 부수어휘(fringe vocabulary)는 무수히 많은 낱말로 구성된 저빈도 어휘로 명사가 대 부분을 차지한다. 핵심어휘와 달리 여러 사람에 의해 공통적으로 사용되기보다는 상당히 개별화되어 사용되거나 특정 상황에서만 사용된다(Boenisch \& Soto, 2015; Marvin et al., 1994; Robillard et al., 2014).

효과적인 의사소통을 하기 위해서는 핵심어휘와 부수어휘를 둘 다 AAC 체계에 포함시켜야 하겠지만(Balandin \& Iacono, 1998; Beukelman et al., 1991; Yorkston, Honsinger, Dowden, \& Marriner, 1989), 다음과 같은 특징들 때문에 핵심어휘는 AAC 중재 시 보 다 중요하게 고려되고 있다. 위에서 언급하였듯이 상대적으로 적은 수의 낱말들로 다양한 환경에서 여러 사람에 의해 사용되기 때문 에 낱말 하나가 가지고 있는 효율성이 높다. 특히 의사소통판이나 의사소통책과 같이 비전자적 도구를 사용하는 경우에는 어휘를 담아낼 수 있는 물리적 공간이 제한되기 때문에 활용도가 높은 핵 심어휘를 우선적으로 배치하여 보다 효과적인 중재 효과를 기대할 수 있다(Morris \& Newman, 1993; Yorkston et al., 1989). 아울러 핵 심어휘를 전자적 또는 비전자적 $\mathrm{AAC}$ 장치의 고정된 위치에 배치 할 경우, 반복된 선택동작을 통해 목표 낱말의 위치에 대한 학습이 쉽게 이루어지므로 움직임의 자동화(automaticity)를 통해 낱말탐 색에 요구되는 인지적 부담을 줄일 수 있다(Boenisch \& Soto, 2015). 또한 핵심어휘에는 문법적인 기능을 하는 구조어와 함께 내용어인 고빈도 동사가 다수 포함되어 있기 때문에 $\mathrm{AAC}$ 사용자로 하여금 낱말들을 결합하여 다양한 구문의 문장을 생성해 낼 수 있도록 해 준다(Marvin et al., 1994).

핵심어휘에 대한 연구는 주로 아동을 대상으로 이루어져 왔다 (예: Banajee et al., 2003; Beukelman et al., 1989; Boenisch \& Soto, 2015; Crestani, Clendon, \& Hemsley, 2010; Fallon et al., 2001; FriedOken \& More, 1992; Kim \& Han, 2016; Lee \& Park, 2006; Lee, 2004; Lee, Kim, \& Park, 2005; Marvin et al., 1994; Park \& Kim, 2003; Trembath et al., 2007). 그러나 Seong, Lim, Kim과 Park (2013)의 보고에 따르면 $\mathrm{AAC}$ 중재가 필요할 것으로 추정되는 국내의 후천적인 의 사소통장애 성인환자의 수는 약 31 만 3,690명으로 추산되고 있다. 이는 영유아와 아동을 포함한 전체 AAC 잠재수요자의 $92 \%$ 를 상
회하는 높은 비율이다. 따라서 $\mathrm{AAC}$ 를 필요로 하는 성인환자의 수 요에 맞추어 이들에게 제공할 수 있는 $\mathrm{AAC}$ 어휘체계를 확립하는 것이 필요하다. 비록 몇몇 영어권 연구들이 성인의 발화샘플을 토대 로 핵심어휘를 제공하고는 있으나(Balandin \& Iacono, 1999; Stuart et al., 1997), 한국의 언어체계와는 다르기 때문에 국내 성인 사용 자에게 그대로 적용하기에는 한계가 있다.

그런 의미에서 성인을 대상으로 AAC 어휘를 조사한 Kim 등(2003) 과 Park과 Kim (2015)의 연구가 갖는 의의는 크다. Kim 등(2003)은 정상 성인 20명과 고등학생 8 명을 대상으로 다양한 대화상황에서 수집된 총 3,772 개의 낱말로 구성된 전체발화샘플에 대해 $2 \%$ 이상 의 빈도율을 보인 낱말들을 고빈도 어휘로 분류하여 제시하였다. 아울러 총 9 개의 대화상황 중 5 개 이상의 상황에서 출현하면서 전 체 발화에서 10 회 이상 사용한 낱말들도 함께 제시하였다. 높은 공 통성과 고빈도의 특징을 동시에 충족하는 34 개의 낱말을 살펴보면 상당수가 대명사, 동사, 부사인 것으로 나타났다(예: ‘하다', ‘주다', '가다, ‘보다', ‘이거', ‘여기', ‘다'). Park과 Kim (2015)은 지적장애가 있는 성인을 대상으로 가정상황, 식사상황, 그리고 커뮤니티 활동 상황 중에 이루어지는 대화를 수집하여 영어권 $\mathrm{AAC}$ 연구에서 주 로 사용하는 .5\% 이상의 빈도율 기준을 적용하여 310 개의 낱말로 구성된 핵심어휘를 판별하였다. 이들 어휘는 총 12,007 개의 낱말로 이루어진 전체발화샘플의 $84.73 \%$ 를 설명해주는 것으로 나타났다.

비록 국내의 선행연구가(Kim et al., 2003; Park \& Kim, 2015) 한 국 성인의 발화에 나타난 고빈도 기본형 용언을 파악하는 데에 중 요한 정보를 제공하고는 있으나 임상현장에 결과를 바로 적용하기 에는 몇 가지 제한점이 있어 보인다. Kim 등(2003)의 연구에서는 수집된 샘플의 낱말수가 상황별로 통제되어 있지 않기 때문에 특 정 상황에서 많이 수집된 낱말들이 전체 발화샘플에서의 빈도수 를 높여서 고빈도 어휘 판별에 영향을 주었을 가능성이 있다(Hess, Sefton, \& Landry, 1986). 가령 가정상황에서 수집된 총 낱말수는 1,208 개로 병원상황의 155 개와 비교하면 편차가 큰 편이다. 또한 연 구자들이 사용한 고빈도 어휘의 기준인 상위 $2 \%$ 빈도율의 근거가 불명확하다. Park과 Kim (2015)의 연구에서는 영어권의 AAC 어휘 연구에서 주로 사용하는 $.5 \%$ 의 기준을 적용하여 핵심어휘를 판 별하고 있으나 영어와 언어체계가 다른 한국어에 바로 적용하기에 는 적합성이 검증되지 않았고, 이 기준점 또한 핵심어휘와 부수어휘 를 분명하게 구분하지 못하는 것으로 보고되고 있다(Shin \& Hill, 2016).

Beukelman 등(1989)은 .5\%o 이상의 빈도율을 보이는 250개의 낱말들이 전체 발화의 대부분인 $85 \%$ 를 설명해준다고 보고하였고, 이후 많은 연구들의 핵심어휘 판별 기준으로 사용되어 왔다. 그러 
나 이들이 제시하는 누적비율그래프(cumulated rate graph)를 살 펴보면, $x$ 축의 누적된 낱말 빈도순위와 $y$ 축의 누적된 설명력 간에 선형관계가 나타나 어느 순위 또는 빈도율의 낱말부터 핵심어휘로 분류할지를 결정하기가 모호해진다(Shin \& Hill, 2016). 또한 그래 프의 $x$ 축과 $y$ 축에 사용된 서로 다른 성격의 척도 때문에 낱말의 빈 도와 설명력 사이의 관계를 양적으로 명확하게 해석하는 데에도 어려움이 있다. 다시 말하면, $\mathrm{x}$ 축에 사용된 낱말의 누적된 빈도순 위는 순서척도(ordinal scale)로 순위 간의 간격이 동일하지 않은 반 면 y축에 나타나는 설명력(\%)은 측정 단위들 간의 간격이 동일한 비율척도(ratio scale)를 사용하기 때문에 그래프에 나타난 $\mathrm{x}$ 변수의 증가량에 대한 $\mathrm{y}$ 변수의 증가량을 단순하게 해석할 수 없게 된다.

이상의 제한점들을 보완하여 Shin과 Hill (2016)은 성인 12명을 대상으로 누적비율그래프가 아닌 묶음빈도분포(grouped frequency distribution)을 사용하여 핵심어휘를 판별한 바 있다. 묶음빈도 분포란 변수를 일정한 급간으로 묶어서 분석하는 방법으로 변수 의 범위가 크고 사례수가 많은 데이터에 대하여 효과적으로 전체 분포의 양상을 파악하는 데에 도움을 주는 것으로 알려져 있다 (Gravetter \& Wallnau, 2013; Portney \& Watkins, 2009). 이 방법은 $\mathrm{x}$ 축에 놓이게 되는 빈도구간에 따라 그에 상응하는 서로 다른 낱 말수를 $\mathrm{y}$ 축에 나타낼 수 있기 때문에 핵심어휘의 특징으로 파악할 수 있는 빈도와 서로 다른 낱말수 간의 관계를 쉽게 파악할 수 있도 록 해준다. Shin과 Hill (2016)은 한국어의 경우 $.5 \%$ 이 아닌 .2\%o을 기준으로 고빈도 어휘구간과 저빈도 어휘구간이 나뉜다는 것을 밝 혀내었다.

그러나 이들의 연구는 Kim 등(2003), Park과 Kim (2015)과 다르 게 한국어의 특징인 다양한 용언의 어미 활용(conjugative endings) 을 핵심어휘 목록에서 확인하고자 하였기 때문에 용언의 기본형이 아닌 활용형이 그대로 빈도분석에 반영되어 있다. 비록 시제, 존칭, 문장유형과 같은 다양한 문법적인 기능을 담당하는 어미들이 AAC 어휘를 배치할 때에 고려되어야 한다는 근거를 제공하나 각각의 활 용형 용언을 그대로 $\mathrm{AAC}$ 에 적용하는 것이 효과적인 $\mathrm{AAC}$ 어휘선 택과 배치로 이어질지에 대해서는 아직 논의가 이루어지지 않았다. 한국어의 경우 용언활용의 범위가 영어에 비하여 광범위 하고( $\mathrm{Ihm}$, Hong, \& Chang, 2001; Yeon \& Brown, 2011), 고빈도 활용형 용언 을 핵심어휘에 포함할 경우 영어권보다 설명력이 낮게 나타날 수 있 으므로(Shin \& Hill, 2016) 다양한 어미와 자유롭게 결합하여 사용 할 수 있는 용언의 기본형에 초점을 맞출 필요가 있다. 따라서 본 연 구에서는 효과적인 한국형 $\mathrm{AAC}$ 체계를 구축하기 위하여 고빈도 기본형 용언을 파악하고 그 효율성과 설명력을 살펴보고자 하였다. 연구질문은 다음과 같다.
첫째, 고빈도 기본형 용언에는 어떠한 낱말들이 포함되는가?

둘째, 용언의 활용형을 기본형으로 변형하였을 때, 고빈도 용언에 포함되는 낱말수는 변하는가?

셋째, 용언의 활용형을 기본형으로 변형하였을 때, 고빈도 용언 의 평균사용빈도는 변하는가?

넷째, 용언의 활용형을 기본형으로 변형하였을 때, 고빈도 용언 이 전체발화샘플에 대해 보이는 설명력(\%)은 변하는가?

\section{연구 방법}

본 연구에 사용된 발화샘플은 Shin과 Hill (2016)이 한국형 AAC 핵심어휘 목록의 개발을 위하여 미국에 거주하는 한국인을 대상 으로 수집한 발화샘플에 기반하고 있다. 연구대상, 발화샘플의 수 집 및 빈도분석 절차를 요약하면 다음과 같다.

\section{연구 대상}

한국어를 모국어로 사용하는 20 대에서 30 대로 구성된 12 명의 정상성인(남성 6 명, 여성 6 명, 평균연령 $=31.42$ 세, $\mathrm{SD}=3.65$ )이 연 구에 참여하였다. 이들은 모두 학사졸업 이상의 학력을 가졌고 국 외 거주기간이 5 년 이내(평균 $=2.69$ 년, $\mathrm{SD}=1.62$ )이며 영어보다는 한국어로 의사소통하기가 수월하다고 보고한 이들이다. 발화샘플 의 크기 $(\mathrm{N}=12)$ 는 문헌에서 보고된 몇몇 $\mathrm{AAC}$ 어휘 연구의 샘플크 기를 상회하며[예: 5명의 발화샘플에 기반한 Beukelman 등(1989) 과 Fallon 등(2001)], 비영어권에서 핵심어휘를 효과적으로 판별한 Chen, Hill 그리고 Yao (2009)의 발화샘플과 동일한 크기이다. 모든 피험자들은 신경·정신적 병력이 없으며 언어병리학적 진단을 받은 바가 없었던 것으로 확인되었다. Korean version of Mini Mental State Examination (K-MMSE; Kang, Na, \& Hahn, 1997)을 통해 인 지능력에 결함이 없고(평균 29.92점/30점 만점, $\mathrm{SD}=.29$ ), KoreanWestern Aphasia Battery (K-WAB; Kim \& Na, 2004) 검사의 하위 검사를 통해 청각적 이해능력에도 문제가 없는 이들이 참여하였다 (평균 199.83점/200점 만점, $\mathrm{SD}=.58$ ).

\section{발화샘플의 수집절차}

발화샘플은 독립되고 조용한 방에서 동일한 연구자와의 비구조 화된 1:1 대화상황에서 수집되었다. 주로 연구가 늦은 오후 시간대 에 진행되었기 때문에 연구자는 피험자의 발화를 유도하기 위하여 “오늘 무엇을 하셨나요?”라는 공통된 질문을 하였고, 이후의 주제 는 자발적으로 피험자가 선택하였다. 대화가 중단된 경우, 연구자 는 피험자의 발화 내용을 토대로 질문을 하여 대화를 확장해나가 
도록 하였다. 대화는 약 45 분간 진행되었으며 모든 발화는 전사를 위하여 녹음되었다. 피험자들마다 전사된 총 낱말수가 다르기 때 문에 이로 인한 영향을 통제하기 위하여(Hess, et al., 1986) 가장 적 은 수의 낱말로 구성된 샘플에 맞추었다(word-level cut). 분석을 위 해 사용된 전체발화샘플의 총낱말수는 16,944 (즉, $1,412 \times 12$ 개의 샘플)이고 활용형 용언을 포함한 서로 다른 낱말수는 3,669 였다. 빈 도분석을 하기에 앞서 전체 샘플의 $15 \%$ 에 대하여 한국어가 모국어 인 언어병리학 박사과정에 있는 학생이 전사를 하였고, point-bypoint agreement (Kazdin, 2011)에 기반한 검사자 간의 신뢰도를 구 한 결과 $95.38 \%$ 의 높은 신뢰도를 보이는 것으로 나타났다.

\section{고빈도 어휘 판별}

전체발화샘플에 대하여 IBM SPSS Statistics version 22를 통해 묶음빈도를 분석한 결과 . $2 \% 0$ 을 기준으로 627 개의 낱말로 구성된 고빈도 어휘와 3,042 개의 낱말로 구성된 저빈도 어휘로 나뉘는 것 이 확인되었다. 이들 고빈도 어휘는 전체발화샘플의 $75.83 \%$ 를 설명 해주는 것으로 나타났다. Shin과 Hill (2016)에서 조작적으로 정의 한 핵심어휘에 따라 $.2 \%$ 이상의 고빈도 어휘에 속하면서 전체 피 험자의 $50 \%$ 이상으로부터 공통적으로 사용된 어휘를 판별한 결과 219 개의 낱말이 확인되었다. 이들은 일반적으로 고빈도 어휘를 핵 심어휘로 정의한 연구들(Banajee et al., 2003; Beukelman et al., 1989; Crestani et al., 2010; Fallon et al., 2001; Liu \& Sloane, 2006; Marvin et al., 1994; Stuart et al., 1997; Trembath et al., 2007)과 달리 고빈도 이면서 공통성이 높다는 핵심어휘의 개념적인 특징을 조작적 정의 에 반영하여 어휘선정의 준거로 사용하였다. 따라서 이들이 보고 한 핵심어휘는 627 개의 고빈도 어휘와 달리 낱말수가 적으며 그 만 큼 설명력도 $60.82 \%$ 로 크게 감소된 것으로 나타났다. 제한된 수의 용언으로 높은 설명력이 보여지는지를 확인하는 것이 본 연구의 목 적이고 설명력은 $\mathrm{AAC}$ 어휘 판별에 중요한 판단기준이므로(Beukelman et al., 1989, 1991) 설명력이 낮은 219개의 핵심어휘에 포함 된 용언이 아닌 상대적으로 설명력이 높은 627 개의 고빈도 어휘에 포함된 용언에 대하여 분석이 이루어졌다.

\section{용언의 기본형 분석}

고빈도 어휘에 포함된 216 개의 활용형 용언을 모두 기본형으로 변형한 후(예: ‘하면서' $\rightarrow$ ‘하다'), Microsoft Excel 프로그램의 ‘중복 된 항목 제거' 기능을 이용하여 고빈도 기본형 용언에 포함되는 낱 말을 판별하고 서로 다른 낱말수를 확인하였다. 아울러 이들 낱말 들에 대하여 다음의 측정변수들을 계산하였다.
(1) 서로 다른 낱말수의 감소율

$=\frac{\text { 고빈도 활용형 용언의 서로 다른 낱말수 - 고빈도 기본형 용언의 서로 다른 낱말수 }}{\text { 고빈도 활용형 용언의 서로 다른 낱말수 }} \times 100$

(2) 고빈도 기본형 용언의 평균사용빈도

$$
=\frac{\text { 전체발화샘플에서의 고빈도 기본형 용언의 총 사용빈도 }}{\text { 고빈도 기본형 용언의 서로 다른 낱말수 }}
$$

(3) 고빈도 기본형 용언의 설명력

$$
=\frac{\text { 전체발화샘플에서 모든 용언의 총 사용빈도 }}{\text { 전체발화샘플에서 고빈도 기본형 용언의 총 사용빈도 }} \times 100
$$

고빈도 활용형 용언의 낱말수, 평균사용빈도, 설명력과 비교하기 위하여 (1), (2), (3)에 사용된 계산법을 활용형에도 적용하였다. 또 한 품사별로 고빈도 기본형 용언이 전체발화샘플의 용언에 대하여 보이는 낱말수와 설명력에 차이가 있는지를 살펴보기 위하여 (1)과 (3)의 계산을 품사별로도 실시하였다.

\section{연구 결과}

\section{고빈도 기본형 용언}

활용형에서 기본형으로 어형을 변형시킨 후 확보한 고빈도 기본 형 용언은 Appendix 1에 목록으로 제시되어 있다. 고빈도 활용형 용언이 서로 다른 216 개의 낱말로 이루어졌던 것에 비하여 기본형 은 63개의 서로 다른 낱말로 구성되었다. 고빈도 기본형에는 35 개 의 동사, 18 개의 형용사, 8 개의 보조동사, 그리고 2 개의 계사가 포함 된 것으로 나타났다. 용언의 하위품사별로 고빈도 기본형 어휘에 포함된 낱말과 전체발화샘플에 나타난 빈도율을 살펴보면 다음과 같다.

동사로는 빈도율의 내림차순으로 ‘하다'(25.26\%), '되다'(10.03\%), '보다'(6.73\%), '그리하다'(6.49\%), '오다'(4.01\%), '가다'(3.72\%), '모르다'(3.07\%), '들다'(2.12\%0), '알다'(2.07\%), '나오다'(1.89\%0), '듣다'( $1.83 \%$ ) , '대하다'(1.53\%), '못하다'(1.48\%), '만들다'( $1.36 \%)$, '받다'(1.36\%), '생각하다'(1.24\%), '이리하다’ $(1.12 \% 0)$, '맞다'(1.12\%), '애기하다'(1.00\%), '좋아하다'(.89\%), '주다'(.89\%), '먹다'(.89\%), '가르치다'(.77\%), '뽑다'(.77\%), '느끼다'(.71\%), '배우다'(.71\%), '보이다'(.71\%), '어찌하다'(.59\%), '가지다'(.53\%), '위하다'(.47\%), '따르다'(.41\%), '관련되다'(.35\%), '불구하다'(.35\%), '통하다'(.35\%), '커버하다'(.24\%)가 포함되었다.

형용사로는 '있다'( $16.41 \%)$, '같다'( $(11.80 \%)$, '그렇다'( $7.67 \%)$, '없 다'(5.90\%), '이렇다'(3.72\%), '많다'(3.31\%), '좋다'(3.01\%), '어떻다' 
(1.95\%), '힘들다'( $1.36 \%$ ), '크다'( $1.24 \%$ ), '중요하다'( $1.18 \%$ ), '싫다' (1.06\%), '쉽다'(.71\%o), '비슷하다'(.59\%), '재미있다'(.53\%), '편하다' $(.53 \%)$, '새롭다' $(.35 \%)$ ) '작다' $(.24 \%$ o)가 포함되었다.

보조동사로는 '있다'(4.84\%o), '가지다'(4.19\%), '않다'(3.36\%o), '하다'(3.01\%), '보다'(2.71\%), '주다'(2.24\%), '싶다'( $1.12 \%$ ), '놓다' $(.94 \%)$ 가 포함되었고, 계사로는 '이다'(22.84\%o)와 '아니다'(6.26\%) 가 포함되었다.

\section{고빈도 용언의 낱말수 비교}

Table 1에 나타난 바와 같이 고빈도 용언의 낱말수 감소율을 계 산한 결과 기본형의 낱말수가 전반적으로 활용형보다 $70.83 \%$ 감소 된 것으로 나타났다. 품사별로 살펴보면 계사의 감소율이 $93.75 \%$ 로 가장 높았으며, 형용사(70.49\%), 동사(65.35\%), 보조동사(63.64\%)의 순으로 감소율을 보였다.

\section{고빈도 용언의 평균사용빈도 비교}

고빈도 용언 하나가 전체발화샘플의 용언에 대하여 보이는 평균 사용빈도가 Table 2에 활용형과 기본형별로 제시되어 있다. 고빈도 기본형의 경우 63 개의 용언이 전체발화샘플에서 총 3,391 회 사용되 었으며 기본형 하나가 평균 53.83회 사용된 것으로 나타났다. 고빈도 활용형의 경우 216 개의 용언이 전체발화샘플에서 총 2,326 회 사용도 었으며 활용형 하나의 평균사용빈도는 10.77 회인 것으로 나타났다.

Table 1. Reduction rates of the number of different HF predicates by the POS

\begin{tabular}{lccc}
\hline $\begin{array}{l}\text { POS of HF } \\
\text { predicates }\end{array}$ & $\begin{array}{c}\text { Number of different } \\
\text { inflected forms (A) }\end{array}$ & $\begin{array}{c}\text { Number of different } \\
\text { base forms (B) }\end{array}$ & $\begin{array}{c}\text { Reduction } \\
\text { rate (\%) }\end{array}$ \\
\hline Verbs & 101 & 35 & 65.35 \\
Adjectives & 61 & 18 & 70.49 \\
Auxiliary verbs & 22 & 8 & 63.64 \\
Copula & 32 & 2 & 93.75 \\
Total & 216 & 63 & 70.83 \\
\hline
\end{tabular}

$\mathrm{HF}=$ high-frequency; $\mathrm{POS}=$ part-of-speech .

Reduction rate $=\frac{A-B}{A} \times 100$.

Table 3. Accountability of the HF base forms by the POS

\begin{tabular}{lccc}
\hline POS of predicates & $\begin{array}{c}\text { Total frequency of the } \\
\text { predicate (A) }\end{array}$ & $\begin{array}{c}\text { Total frequency of the } \\
\text { HF base form (B) }\end{array}$ & B/A (\%) \\
\hline Verbs & 2,397 & 1,475 & 61.54 \\
Adjectives & 1,287 & 1,043 & 81.04 \\
Auxiliary verbs & 407 & 380 & 93.37 \\
Copulas & 493 & 493 & 100 \\
Total & 4,584 & 3,391 & 73.97 \\
\hline
\end{tabular}

$H F=$ high-frequency; POS= part-of-speech .

\section{고빈도 용언의 전체발화샘플에 대한 설명력 비교}

총 4,584개의 낱말로 구성된 전체발화샘플의 용언에 한정하여 고빈도 기본형 용언의 설명력을 계산한 결과 Table 3 과 같이 $73.97 \%$ 의 설명력을 보이는 것으로 나타났다. 품사별로 살펴보면 계사는 두 개의 낱말(즉, '이다', '아니다')이 전체발화샘플에 나타난 모든 계사를 설명하였고, 그 다음으로 기본형 보조동사와 형용사가 각 각 $93.37 \%$ 와 $81.04 \%$ 로 비교적 높은 설명력을 보였다. 반면에 고빈 도 기본형 동사는 $61.54 \%$ 의 상대적으로 낮은 설명력을 보였다.

고빈도 활용형 용언이 전체발화샘플의 용언에 대하여 보이는 설 명력은 기본형일 때보다 더 낮아지는 것으로 나타났다. Table 4에 나타난 바와 같이 고빈도 활용형은 $50.74 \%$ 의 설명력을 보여 기본형 일 때보다 약 $23.23 \%$ (즉, $73.97 \%-50.74 \%$ )의 차이를 보였다. 품사별 로 살펴보면 기본형과 마찬가지로 계사가 가장 높은 설명력을 보였 으나 기본형보다 $26.57 \%$ 낮은 수치이며, 형용사와 보조동사는 기 본형보다 각각 $17.40 \%$ 와 $33.91 \%$ 정도 낮았다. 동사는 기본형과 마 찬가지로 가장 낮은 설명력을 보였고 이 역시 $23.87 \%$ 정도 감소하 였다.

총 16,944 개의 낱말로 구성된 전체발화샘플로 범위를 확장하여 고빈도 기본형과 활용형의 설명력을 비교한 결과 기본형은 $82.11 \%$ 의 설명력을 보였고 이는 활용형의 설명력인 $75.83 \%$ 보다 $6.28 \%$ 정 도 높은수치였다.

Table 2. Accountability of $64 \mathrm{HF}$ predicates and the mean frequency of a single HF predicate

\begin{tabular}{lcc}
\hline & \multicolumn{2}{c}{ HF predicates } \\
\cline { 2 - 3 } & Inflected forms & Base forms \\
\hline Number of different words in HF predicates (A) & 216 & 63 \\
Total frequency of HF predicates (B) & 2,326 & 3,391 \\
Mean frequency of a single HF predicate (B/A) & 10.77 & 53.83 \\
\hline
\end{tabular}

$H F=$ high frequency.

Table 4. Accountability of the HF inflected forms by the POS

\begin{tabular}{lccc}
\hline POS of predicates & $\begin{array}{c}\text { Total frequency of the } \\
\text { predicate (A) }\end{array}$ & $\begin{array}{c}\text { Total frequency of the } \\
\text { HF base form (B) }\end{array}$ & B/A(\%) \\
\hline Verbs & 2,397 & 903 & 37.67 \\
Adjectives & 1,287 & 819 & 63.64 \\
Auxiliary verbs & 407 & 242 & 59.46 \\
Copulas & 493 & 362 & 73.43 \\
Total & 4,584 & 2,326 & 50.74 \\
\hline
\end{tabular}

$H F=$ high-frequency; POS= part-of-speech. 


\section{논의 및 결론}

본 연구에서는 정상성인의 발화샘플을 중심으로 고빈도 용언의 기본형을 파악하고 활용형과 비교하여 얼마나 적은 수의 낱말들로 많은 설명력을 보일 수 있는지를 살펴보았다. 첫 번째 연구질문과 관련하여 $\mathrm{AAC}$ 핵심어휘로 고려될 수 있는 용언의 고빈도 기본형 을 분석한 결과 동사 35 개, 형용사 18 개, 보조동사 8 개, 계사 2 개로 구성된 총 64개의 고빈도 용언이 판별되었다. 빈도분석 방법이 다 르기 때문에 선행연구와의 직접적인 비교는 어려우나 이들 낱말은 영어권 AAC 연구에서 보고된 핵심어휘(Balandin \& Iacono, 1999; Stuart et al., 1997)에 포함된 용언의 기본형과 대부분 일치하였다. 그러나 국내연구와 비교하였을 때에는 정상 청소년과 성인에 대하 여 상황별로 전체 낱말 빈도수 중 $2 \%$ 이상 출현한 낱말을 고빈도 어 휘로 분류한 Kim 등(2003)과는 $59.09 \%$ 의 용언 일치도를 보이는 것 으로 나타났다. 즉 Kim 등(2003)이 보고한 22개의 용언 중에서 다음 의 13 개 낱말이 두 연구에서 공통적으로 포함되었다('되다', '주다',

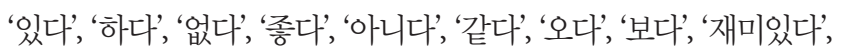
'나오다, '어떻다'). 지적장애가 있는 성인의 고빈도 용언과는 일치도 가 더 낮아지는 것으로 나타났다. 전체 낱말에 대한 빈도율이 $.5 \%$ 이상인 낱말을 핵심어휘로 분류한 Park과 Kim (2015)의 연구에서 는 총 109 개의 고빈도 용언이 소개되고 있는데 이 중 31 개(28.44\%) 만이 본 연구의 고빈도 용언와 일치하였다. 포함된 어휘로는 '하다', '가다', '아니다', ‘오다', ‘되다', '있다', '먹다', '보다', '주다', '많다', '없 다', '가지다', '놓다', '그렇다’, '않다', '같다', '받다', ‘들다', '나오다', '좋다, '모르다', '재미있다', '알다', '맞다', '싶다', '싫다', ‘좋아하다', '보이다', '만들다', '힘들다', '크다' 였다. 낮은 일치도의 원인으로는 위에서도 언급한 바와 같이 낱말의 빈도분석 방법이 연구마다 서 로 다르기 때문일 수도 있으나 선행연구에서는(예: Kim et al., 2003) 발화샘플들 간의 통제되지 않은 낱말수가 낮은 일치도에 영향을 주었을 가능성을 배제할 수 없다.

연구질문 2 와 관련해서는 고빈도 용언의 개수가 활용형에서 기 본형으로 변형되었을 때 높은 감소율을 보이는 것으로 나타났다. 낱말수의 감소율은 품사마다 조금씩 차이가 있는 것으로 나타났 다. 동사, 형용사, 보조동사는 $60 \%-70 \%$ 초반대의 감소율을 보인 반 면 계사는 $90 \%$ 대의 높은 감소율을 보였다. 이는 계사의 기본형이 실제 발화에서는 다른 용언의 유형들보다 훨씬 다양한 형태로 활 용되었다는 것을 의미한다. 낱말수의 감소폭이 크다는 본 연구의 결과는 63 개의 기본형을 중심으로 다른 어미와의 결합을 통해 다 양한 용언이 표현될 수 있다는 것을 말해주기 때문에 $\mathrm{AAC}$ 어휘를 선택하고 배치하는 데에 중요한 역할을 하는 언어치료사에게 상당
히 고무적인 결과로 볼 수 있다. 만약 $\mathrm{AAC}$ 체계에 우선적으로 고려 해야 하는 고빈도 용언의 수가 많다면 다른 중요한 핵심어휘들과의 공간배치 문제를 야기할 수 있다. 그러나 적은 수의 기본형을 $\mathrm{AAC}$ 체계에 우선적으로 반영할 수 있게 됨으로써 어휘배치에 대하여 보다 융통성을 발휘할 수 있을 것이다. 아울러 사용자 입장에서는 자주 사용하는 용언을 선택하기까지 소요되는 탐색시간과 인지적 부담이 줄어들 수 있을 것이다(Morris \& Newman, 1993; Yorkston et al., 1989).

연구질문 3은 고빈도 기본형 용언이 활용형과 비교하여 평균사 용빈도에 차이가 있는지를 살펴보는 것이었다. 낱말수가 용언의 형 태별로 차이가 났기 때문에 평균사용빈도 또한 차이가 나는 것으 로 연구결과 나타났다. 고빈도 용언의 기본형 낱말 한 개의 평균사 용빈도는 활용형일 때보다 다섯 배 증가되는 것으로 나타났다. 이 러한 결과는 $\mathrm{AAC}$ 사용자가 활용형 용언의 개별상징을 사용하는 횟수보다 기본형 상징을 사용하는 횟수가 크게 증가할 수 있다는 것을 시사한다. 따라서 기본형 용언을 통해 AAC 상징의 높은 효율 성을 기대할 수 있게 된다.

또한 용언을 기본형으로 바꾸는 것만으로도 전체 샘플에 대한 설명력이 높아지는 것으로 나타났다. 이는 연구질문 4 와 관련이 있 다. 총 발화샘플에 대하여 고빈도 기본형이 보인 설명력은 활용형 보다 $6.28 \%$ 증가한 $82.11 \%$ 로 나타났다. 이는 비록 분석방법의 차이 가 있기는 하지만 영어권의 $\mathrm{AAC}$ 연구에서 대부분의 전체발화를 설명해주는지 살펴보는 지표로 사용되는 범위인 78\%-85\%에 포함 되는 수치이기도 하다(Balandin \& Iacono, 1999; Banajee et al., 2003; Beukelman et al., 1989; Hill, 2001; Stuart et al., 1997). 전체발화샘 플에 포함된 용언에만 국한하였을 경우 기본형의 설명력은 더욱 뚜 렷하게 높아지는 것으로 나타났다. 전체발화샘플의 총 용언에 대한 기본형 용언의 설명력은 $73.97 \%$ 로 활용형일 때의 $50.74 \%$ 보다 $23.23 \%$ 증가하였고 동사, 형용사, 계사, 보조동사에 걸쳐 설명력이 증가된 것으로 나타났다.

설명력이 높아진다는 의미는 대화상황에서 다양한 주제에 대하 여 발화를 할 때에 사용된 용언의 $73.97 \%$ 를 고빈도 기본형 용언 63 개가 어미활용을 통해 표현해 낼 수 있다는 것을 의미한다. 한국어 와 같이 어간에 문법적인 기능을 가진 어미가 결합하여 문장 속에 서 동사의 다양한 의미와 문법적인 역할을 나타내는 교착어는 기 존의 영어권에서 접근해오는 $\mathrm{AAC}$ 어휘분석 방법을 그대로 적용 하는 데에 무리가 있다(Shin \& Hill, 2016). 그 이유는 영어와 달리 한국어는 체계적이고 방대한 종류의 어미결합과 복수의 어미첨가 가 가능하기 때문에(Ihm et al., 2001; Yeon \& Brown, 2011), 기존의 영어권에서 실시한 분석방법대로 용언의 활용형을 기반으로 어휘 
를 판별할 경우 설명력이 낮아지기 때문이다. 따라서 본 연구는 기 본형의 설명력이 증가된다는 것을 보고함으로써 한국어와 같은 교 착어의 특징을 지닌 다른 언어권(예: 터키어, 일본어, 핀란드어 등) 의 $\mathrm{AAC}$ 어휘 연구에도 어느 정도 지침을 제공하리라 기대한다.

설명력을 품사별로 분석하면서 발견된 흥미로운 점은 고빈도 기 본형 동사는 다른 품사에 비하여 상대적으로 낮은 설명력을 보였다 는 것이다. 이는 실제로 대화상황의 발화에서 저빈도의 다양한 동 사 어휘들이 많이 사용되었다는 것을 시사한다. 따라서 개별적인 $\mathrm{AAC}$ 사용자가 사용하는 중요한 부수어휘를 파악하는 것이 고빈 도 동사를 $\mathrm{AAC}$ 체계에 반영하는 것 못지않게 중요하다는 선행연 구의 주장을 뒷받침한다고 볼 수 있겠다(Balandin \& Iacono, 1998; Beukelman et al., 1991; Yorkston et al., 1989).

본 연구는 기본형 용언의 높은 낱말수 감소율, 평균사용빈도, 설 명력을 밝혀냄으로써 AAC 사용자들이 보다 효율적으로 용언의 활용을 수행할 수 있는 도구개발의 기틀을 마련하였다. 이는 성인 $\mathrm{AAC}$ 사용자뿐만 아니라, 구문적인 지식을 형성 및 학습해 나가야 하는 나이가 어린 사용자들에게도 활용 가능할 것이다. 그러나 이 상의 의의에도 불구하고 본 연구는 몇 가지 제한점이 있다. 우선 발 화샘플의 표집이 이루어진 환경이 어휘수집에 영향을 미쳤을 가능 성이 있다. 동일한 연구자가 실험참여자를 대상으로 독립되고 조용 한 방에서 실험을 실시한 환경은 자연스러운 대화상황과 차이가 있을 수 있다. 가령 대화상대자가 친숙하지 않은 연구자라는 점이 대상자의 어휘선택에 영향을 주었을 가능성이 있으며 대화의 상호 작용에도 영향을 주었을 수 있다. AAC 사용자가 다양한 의사소통 기능을 수행할 수 있도록 하기 위하여(Light, 1988), 보다 자연스러 운 일상에서 다양한 사람들과의 상호작용을 하는 가운데에 나타 나는 발화를 표집하여 연구할 필요가 있겠다. 또 다른 제한점은 연 구에 참여한 대상자의 특징이 어휘수집에 영향을 주었을 가능성 이 있다는 것이다. 본 연구는 공교롭게도 20-30대의 고학력자의 발 화샘플을 기반으로 하고 있기 때문에 나이와 학력이 주는 영향을 배제할 수 없다. 이에 대해 아직까지 많은 논의가 이루어지지는 않 고 있으나 연령에 따라 선호하는 대화주제가 다를 수 있다는 보고 가 있으므로(Stuart et al., 1997) 보다 다양한 연령과 학력, 그리고 장애 정도를 어휘수집에 포함할 필요가 있다. 마지막으로 본 연구 에 참여한 대상자들은 비록 한국어로 모국어로 하고 영어보다는 한국어를 사용하는 것을 선호하였으나 이들이 공통적으로 미국에 거주한다는 사실이 어휘의 선택과 대화주제의 선택에 영향을 주었 을 가능성을 완전히 배제할 수 없기 때문에 결과의 해석이 제한적 일수있다.

본 연구는 고빈도 기본형 용언을 파악하고 그 효율성과 설명력
을 살펴보는 데에 주안점을 두었다. 따라서 함께 결합하여 활용될 수 있는 고빈도 어미를 판별하는 추후연구가 필요할 것으로 보인다. 또한 기본형 용언마다 어미와 결합되어 활용되는 정도가 다를 수 있기 때문에, 활용이 낮은 용언의 경우 기본형이 아닌, 활용형을 있 는 그대로 $\mathrm{AAC}$ 체계에 반영하였을 때에 사용자가 보다 효율적으로 사용할 수 있는지를 검증하는 연구가 필요하다. 효과적인 AAC 중 재 서비스의 제공을 위해서는 보다 다양한 화자의 자연스러운 대 화 환경에서 수집된 발화샘플을 토대로 견고한 $\mathrm{AAC}$ 어휘 데이터 베이스를 확충할 필요성도 있을 것이다. 이때 핵심어휘에 포함되어 있지 않은 개별 사용자의 고빈도 용언과 사용빈도는 높지 않으나 상황별로 중요하게 활용될 수 있는 용언의 부수어휘 또한 파악하 는 과정이 수반되어야 할 것이다. 이러한 자료를 토대로 고빈도 기본 형 용언을 중심으로 한 $\mathrm{AAC}$ 체계가 실제로 성인 장애인의 $\mathrm{AAC}$ 수 행에 어떠한 영향을 주는지를 살펴보는 연구가 이루어져야 하겠다. 아울러 장애 정도, 연령, 학력과 같은 개인적 차원의 요인들과 전체 어휘 크기, 샘플 수집 상황과 같은 발화샘플 차원의 요인들이 의사 소통 효율성에 영향을 주는지에 대한 논의도 이루어져야할 것이다.

\section{REFERENCES}

Baker, B., Hill, K., \& Devylder, R. (2000). Core vocabulary is the same across environments. Proceedings of California State University at Northridge Conference, Los Angeles, CA.

Balandin, S., \& Iacono, T. (1998). A few well-chosen words. Augmentative and Alternative Communication, 14, 147-161.

Balandin, S., \& Iacono, T. (1999). Crews, wusses, and whoppas: core and fringe vocabularies of Australian meal-break conversations in the workplace. Augmentative and Alternative Communication, 15, 95-109.

Banajee, M., Dicarlo, C., \& Buras Stricklin, S. (2003). Core vocabulary determination for toddlers. Augmentative and Alternative Communication, 19, 67-73.

Beukelman, D., Jones, R., \& Rowan, M. (1989). Frequency of word usage by nondisabled peers in integrated preschool classrooms. Augmentative and Alternative Communication, 5, 243-248.

Beukelman, D., McGinnis, J., \& Morrow, D. (1991). Vocabulary selection in augmentative and alternative communication. Augmentative and Alternative Communication, 7, 171-185.

Boenisch, J., \& Soto, G. (2015). The oral core vocabulary of typically developing English-speaking school-aged children: implications for AAC practice. Augmentative and Alternative Communication, 31, 77-84. 
Chen, M. C., Hill, K., \& Yao, T. (2009). Preliminary vocabulary frequency findings for Mandarin Chinese AAC treatments. Proceedings of the 3rd International Convention on Rehabilitation Engineering \& Assistive Technology, Singapore.

Crestani, C. A. M., Clendon, S. A., \& Hemsley, B. (2010). Words needed for sharing a story: implications for vocabulary selection in augmentative and alternative communication. Journal of Intellectual and Developmental Disability, 35, 268-278.

Fallon, K. A., Light, J. C., \& Paige, T. K. (2001). Enhancing vocabulary selection for preschoolers who require augmentative and alternative communication (AAC). American Journal of Speech-Language Pathology, 10, 81-94.

Fried-Oken, M., \& More, L. (1992). An initial vocabulary for nonspeaking preschool children based on developmental and environmental language sources. Augmentative and Alternative Communication, 8, 41-56.

Gravetter, F. J., \& Wallnau, L. B. (2016). Statistics for the behavioral sciences. Boston, MA: Cengage Learning.

Hess, C. W., Sefton, K. M., \& Landry, R. G. (1986). Sample size and type-token ratios for oral language of preschool children. Journal of Speech, Language, and Hearing Research, 29, 129-134.

Hill, K. J. (2001). The development of a model for automated performance measurement and the establishment of performance indices for augmented communicators under two sampling conditions (Doctoral dissertation). University of Pittsburgh, PA.

Ihm, H., Hong, K., \& Chang, S. (2001). Korean grammar for international learners. Seoul: Yonsei University Press.

Johnson, J. M., Inglebret, E., Jones, C., \& Ray, J. (2006). Perspectives of speech language pathologists regarding success versus abandonment of AAC. Augmentative and Alternative Communication, 22, 85-99.

Kang, Y., Na, D. L., \& Hahn, S. (1997). A validity study on the Korean MiniMental State Examination (K-MMSE) in dementia patients. Journal of the Korean Neurological Association, 15, 300-308.

Kazdin, A. E. (2011). Single-case research designs: methods for clinical and applied settings (2nd ed.). New York, NY: Oxford University Press.

Kim, H., \& Na, D. L. (2004). Normative data on the Korean version of the Western Aphasia Battery. Journal of Clinical and Experimental Neuropsychology, 26, 1011-1020.

Kim, J. I., \& Han, K. I. (2016). Core vocabulary of preschool children with or without disabilities for augmentative and alternative communication intervention. Journal of Special Children Education, 18, 185-213.

Kim, Y. T., Park, H. J., \& Min, H. K. (2003). School-aged children and adults's core vocabulary for the development of an augmentative and alternative communication tool. Korean Journal of Communication Disorders, 8, 93 110.

Lee, J. E., \& Park, E. H. (2006). Development of ACC core vocabulary list: vocabulary selection strategies based on communication contexts. Journal of Rehabilitation Research, 4, 96-122.

Lee, Y. M. (2004). Study of children's vocabulary in the elementary school setting (master's theis). Ewha Womans University, Seoul, Korea

Lee, Y. M., Kim, Y. T., \& Park, E. H. (2005). A preliminary study for the core and fringe AAC vocabulary used by elementary school students. Korean Journal of Communication Disorders, 10, 134-152.

Light, J. (1988). Interaction involving individuals using augmentative and alternative communication systems: state of the art and future directions. Augmentative and Alternative Communication, 4, 66-82.

Liu, C., \& Sloane, Z. (2006). Developing a core vocabulary for a mandarin Chinese AAC system using word frequency data. International Journal of Computer Processing of Oriental Languages, 19, 285-300.

Marvin, C., Beukelman, D., \& Bilyeu, D. (1994). Vocabulary-use patterns in preschool children: effects of context and time sampling. Augmentative and Alternative Communication, 10, 224-236.

Morris, K., \& Newman, K. (1993). Vocabulary to promote social interaction using augmentative communication devices. Proceedings of 14th Southeast Annual Augmentative Communication Conference, Birmingham, AL, 8592.

Park, E. Y., \& Kim, Y. T. (2003). A study of core and situational vocabulary ratio in augmentative and alternative communication board. Korean Journal of Communication Disorders, 8, 111-126.

Park, H. Y., \& Kim, Y. T. (2015). Analyses of core and fringe vocabulary of adults with intellectual disabilities living in community group homes. Special Education Research, 14, 81-103.

Portney, L. G., \& Watkins, M. P. (2009). Foundations of clinical research: applications to practice (3rd ed.). Upper Saddle River, NJ: Prentice Hall.

Robillard, M., Mayer-Crittenden, C., Minor-Corriveau, M., \& Bélanger, R. (2014). Monolingual and bilingual children with and without primary language impairment: core vocabulary comparison. Augmentative and Alternative Communication, 30, 267-278.

Seong, S. Y., Lim, J. H., Kim, Y. T., \& Park, E. H. (2013). The prevalence of potential AAC users in Korea: from the early childhood to the adulthood. AAC Research \& Practice, 1, 1-24.

Shin, S., \& Hill, K. (2016). Korean word frequency and commonality study 
for augmentative and alternative communication. International Journal of Language and Communication Disorders, 51(4), 415-429.

Stuart, S., Beukelman, D., \& King, J. (1997). Vocabulary use during extended conversations by two cohorts of older adults. Augmentative and Alternative Communication, 13, 40-47.

Trembath, D., Balandin, S., \& Togher, L. (2007). Vocabulary selection for Australian children who use augmentative and alternative communication. Journal of Intellectual and Developmental Disability, 32, 291-301.
Yeon, J., \& Brown, L. (2011). Korean: a comprehensive grammar. London: Routledge.

Yorkston, K., Dowden, P., Honsinger, M., Marriner, N., \& Smith, K. (1988). A comparison of standard and user vocabulary lists. Augmentative and Alternative Communication, 4, 189-210.

Yorkston, K., Honsinger, M., Dowden, P., \& Marriner, N. (1989). Vocabulary selection: a case report. Augmentative and Alternative Communication, 5, 101-108. 
Appendix 1.63개의 고빈도 기본형 용언

\begin{tabular}{|c|c|c|c|}
\hline 순위 & 낱말 & 품사 & 빈도율 $(\%)^{a}$ \\
\hline 1 & 하다 & 동사 & 25.26 \\
\hline 2 & 이다 & 계사 & 22.84 \\
\hline 3 & 있다 & 형용사 & 16.41 \\
\hline 4 & 같다 & 형용사 & 11.80 \\
\hline 5 & 되다 & 동사 & 10.03 \\
\hline 6 & 그렇다 & 형용사 & 7.67 \\
\hline 7 & 보다 & 동사 & 6.73 \\
\hline 8 & 그리하다 & 동사 & 6.49 \\
\hline 9 & 아니다 & 계사 & 6.26 \\
\hline 10 & 없다 & 형용사 & 5.90 \\
\hline 11 & 있다 & 보조동사 & 4.84 \\
\hline 12 & 가지다 & 보조동사 & 4.19 \\
\hline 13 & 오다 & 동사 & 4.01 \\
\hline 14 & 이렇다 & 형용사 & 3.72 \\
\hline 15 & 가다 & 동사 & 3.72 \\
\hline 16 & 않다 & 보조동사 & 3.36 \\
\hline 17 & 많다 & 형용사 & 3.31 \\
\hline 18 & 모르다 & 동사 & 3.07 \\
\hline 19 & 좋다 & 형용사 & 3.01 \\
\hline 20 & 하다 & 보조동사 & 3.01 \\
\hline 21 & 보다 & 보조동사 & 2.71 \\
\hline 22 & 주다 & 보조동사 & 2.24 \\
\hline 23 & 들다 & 동사 & 2.12 \\
\hline 24 & 알다 & 동사 & 2.07 \\
\hline 25 & 어떻다 & 형용사 & 1.95 \\
\hline 26 & 나오다 & 동사 & 1.89 \\
\hline 27 & 듣다 & 동사 & 1.83 \\
\hline 28 & 대하다 & 동사 & 1.53 \\
\hline 29 & 못하다 & 동사 & 1.48 \\
\hline 30 & 힘들다 & 형용사 & 1.36 \\
\hline 31 & 만들다 & 동사 & 1.36 \\
\hline 32 & 받다 & 동사 & 1.36 \\
\hline
\end{tabular}

\begin{tabular}{|c|c|c|c|}
\hline 순위 & 낱말 & 품사 & 빈도율 $(\%)$ \\
\hline 33 & 크다 & 형용사 & 1.24 \\
\hline 34 & 생각하다 & 동사 & 1.24 \\
\hline 35 & 중요하다 & 형용사 & 1.18 \\
\hline 36 & 이리하다 & 동사 & 1.12 \\
\hline 37 & 싶다 & 보조동사 & 1.12 \\
\hline 38 & 맞다 & 동사 & 1.12 \\
\hline 39 & 실다 & 형용사 & 1.06 \\
\hline 40 & 예기하다 & 동사 & 1.00 \\
\hline 41 & 놓다 & 보조동사 & .94 \\
\hline 42 & 좋아하다 & 동사 & .89 \\
\hline 43 & 주다 & 동사 & .89 \\
\hline 44 & 먹다 & 동사 & .89 \\
\hline 45 & 가르치다 & 동사 & .77 \\
\hline 46 & 뽑다 & 동사 & .77 \\
\hline 47 & 느끼다 & 동사 & .71 \\
\hline 48 & 배우다 & 동사 & .71 \\
\hline 49 & 쉽다 & 형용사 & .71 \\
\hline 50 & 보이다 & 동사 & .71 \\
\hline 51 & 비슷하다 & 형용사 & .59 \\
\hline 52 & 어찌하다 & 동사 & .59 \\
\hline 53 & 가지다 & 동사 & .53 \\
\hline 54 & 재미있다 & 형용사 & .53 \\
\hline 55 & 편하다 & 형용사 & .53 \\
\hline 56 & 위하다 & 동사 & .47 \\
\hline 57 & 따르다 & 동사 & .41 \\
\hline 58 & 새롭다 & 형용사 & .35 \\
\hline 59 & 관련되다 & 동사 & .35 \\
\hline 60 & 불구하다 & 동사 & .35 \\
\hline 61 & 통하다 & 동사 & .35 \\
\hline 62 & 작다 & 형용사 & .24 \\
\hline 63 & 커버하다 & 동사 & .24 \\
\hline
\end{tabular}

a빈도율은 해당 낱말이 전체발화샘플에서 나타난 출현빈도를 총 낱말수인 16,944 로 나눈 후 1,000 을 곱하여 산출하였음. 


\section{국문초록}

\section{$A A C$ 체계 구축을 위한 고빈도 용언의 기본형 분석 \\ 신상은}

이화여자대학교 대학원 언어병리학과

배경 및 목적: 핵심어휘는 보완대체의사소통(augmentative and alternative communication, AAC) 사용자들의 성공적인 의사소통을 결정짓는 중요한 요소이다. 본 연구에서는 성인 $\mathrm{AAC}$ 사용자가 다양한 어미와의 결합을 통하여 용언을 활용할 수 있는 $\mathrm{AAC}$ 체계를 구 축하고자 정상성인의 발화샘플을 중심으로 고빈도 용언의 기본형을 판별하고 그 효율성을 살펴보고자 하였다. 방법: 12 명의 정상 성인 으로부터 수집된 발화샘플에서 고빈도로 확인된 216개의 동사, 형용사, 보조동사, 그리고 계사를 축출하였다. 이들 용언의 활용형을 기 본형으로 바꾼 후, 서로 다른 낱말수와 전체 샘플의 용언에 대한 평균사용빈도 및 설명력을 계산하여 기본형으로 바꾸기 전의 수치와 비교하였다. 결과: 고빈도 기본형 용언은 총 64 개로 활용형 용언의 개수보다 $70.83 \%$ 감소하였으며 한 낱말의 평균사용빈도는 53.83 회인 것으로 나타났다. 또한 전체발화샘플에 나타난 용언의 $73.97 \%$ 를 설명해내는 것으로 나타났다. 활용형 용언과 비교하여 평균사용빈도 는 약 5 배 정도 증가하였고 설명력은 $23.23 \%$ 증가하였다. 논의 및 결론: 본 연구는 적은 수의 고빈도 기본형 용언이 어미와의 결합을 통 하여 다양한 용언으로 활용될 수 있다는 것을 증가된 낱말수 감소율, 평균사용빈도 및 설명력을 통하여 보여주었다. 교착어를 특징으 로 하는 한국어, 특히 용언의 어미활용을 $\mathrm{AAC}$ 사용자가 효과적으로 수행할 수 있도록 하기 위한 도구개발과 후속연구들의 필요성이 논의되었다.

핵심어: 핵심어휘, 보완대체의사소통, 용언, 기본형, 고빈도, 성인

본 연구는 Shin과 Hill (2016)의 한국 AAC 핵심어휘 연구 자료를 기반으로 이루어졌음.

\section{참고문헌}

강연욱, 나덕렬, 한승혜(1997). 치매환자들을 대상으로 한 K-MMSE의 타당도연구. 대한신경과학회지, 15, 300-308.

김영태, 박현주, 민홍기 (2003). 보완. 대체의사소통도구 개발을 위한 학령기 아동 및 성인의 핵심어휘 조사. 언어청각장애연구, 8, 93-110. 김종인, 한경임(2016). 보완대체 의사소통 중재를 위한 일반유아와 장애유아의 핵심어휘 연구 특수아동교육연구, 18, 185-213. 박은혜, 김영태(2003). 보완. 대체의사소통판에서의 핵심어휘와 상황어휘 적정 비율에 관한 연구. 언어청각장애연구, 8, 111-126. 박혜연, 김영태(2015). 그룹홈 거주 지적장애 성인의 핵심어휘 및 부수어휘 분석을 통한 의미적 언어사용 연구. 특수교육, 14, 81-103. 이영미(2004). 학령기 아동의 학교 상황 어휘 연구: 보완 대체 의사소통체계 적용을 위한 기초연구. 이화여자대학교 석사학위논문. 이영미, 김영태, 박은혜(2005). 학령기 아동의 학교상황 어휘 연구: AAC 적용을 위한 기초연구. 언어청각장애연구, 10, 134-152. 이정은, 박은혜 (2006). 보완.대체의사소통체계 적용을 위한 상황 중심 핵심어휘 개발 연구. 재활복지, 4, 96-122. 